\title{
EL MITO DE LAS PRIVATIZACIONES Y LA EXPERIENCIA CHILENA*
}

\author{
Por: Jorge Vergara Estévez
}

\section{Resumen}

El autor hace un análisis de los procesos de privatización de empresas y bienes estatales en América latina, para luego detenerse en la experiencia de Chile. Para el caso chileno, se indica que los efectos negativos de las privatizaciones exceden en mucho sus consecuencias positivas, y refutan la teoría neoliberal que ve en ellas una fuente de eficiencia económica y bienestar para todos, confirmando la interpretación del Premio Nóbel de Economía Stiglitz para quien las reformas neoliberales son, básicamente, un proyecto político que significa la radicalización de la dependencia de las economías y los sistemas políticos del mundo periférico a las principales sociedades del Norte, y sus empresas trasnacionales, en función de nuevo ordenamiento de la economía y el sistema de poder mundial, en el contexto de una nueva revolución científico-tecnológica

Jorge Vergara Estévez es Magíster y candidato al Doctorado en filosofía de la Universidad de París 8. Profesor de la Universidad de Chile y editor de Polis de la Universidad Bolivariana (www.revistapolis.cl), de Santiago de Chile. Ha publicado diversos estudios sobre teoría neoliberal en libros y revistas universitarias en Europa y América Latina. Se agradecen los comentarios a vergaraestevez@manquehue.net

\begin{abstract}
In order to examine the Chilean experience the author analyses the privatization process of companies and State Wealth in Latin America. In the case of the Chilean model the negative effects of the privatization exceeds its positive consequences and disputes the neo-liberal theory that is apparent in each one, a source of economic efficiency and welfare for all. In the context of a new technological and scientific revolution, the role of the new economic classification and the world system of power, the neo-liberal reforms are basically, a political project that signifies the radicalization of the economic dependency and of the political structure of the peripheral world to the major developed societies and to its transnational companies. This confirms the interpretation of Stiglitz, who was awarded the Nobel Prize in Economics.
\end{abstract}


“Lo que América Latina necesita es una mezcla cuidadosa de protección, subsidios y promoción de las exportaciones, y no políti-

cas neoliberales de libre comercio y desregulación. Mi libro demuestra que esto es, en efecto, lo que la mayoría de países que actualmente son ricos usaron para desarroIlarse, desde Gran Bretaña en el siglo XVIII, hasta Corea y Taiwán a fines del siglo XX"

Ha-Joon Chang (2003)

“En Chile la privatización no ha llegado sólo al Estado: ha alcanzado el corazón de la política, que junto con desideologizarse ha perdido nivel intelectual y proyección en la opinión. En este aspecto, recobra su significado original la privatización como privación o carencia de referentes a lo que es común. ¿Quedará algo común? En todo caso, a la persona marginada de lo público, al a-ciudadano, se le llamaba en griego idiota: es aquel cuya relación al mundo excluía los asuntos de la ciudad".

\section{Marcos García de la Huerta (2004 b)}

Las privatizaciones continúan siendo un tema central de la política latinoamericana. Durante la década de los noventa, se vendieron decenas de empresas públicas de servicios domiciliarios, petroleras, acerías, y otras (Rivas 2003). “Entre 1990 y 1999, las privatizaciones en América Latina sumaron casi 180.000 millones de dólares. En las 500 mayores empresas de la región, la propiedad extranjera pasó de 27,4 a 43 por ciento y la estatal se contrajo de 33,2 a 18,8 por ciento.
Argentina -considerada entonces un modelo de reducción del Estado se propone ahora revisar privatizaciones y contratos de servicios públicos" (Ips noticias 2003). El afán privatizador no parece tener límites. Se diría que los gobiernos latinoamericanos buscan realizar la utopía del anarquismo neoliberal: "todo es privatizable". Recientemente, el Presidente de Chile, Ricardo Lagos, anunció con orgullo la construcción de la primera cárcel administrada por una empresa privada, siguiendo el modelo norteamericano de empresas carcelarias. Este ha contribuido a que dicho país tenga más de dos millones de presos, la mayor población de reclusos del mundo. Asimismo, los neoliberales en Chile exigen la completa privatización de los servicios públicos de salud y educación.

Sin embargo, las resistencias sociales han sido considerables. Como se sabe, las privatizaciones se han realizado habitualmente contra la opinión de la sociedad civil, ya sea por regímenes dictatoriales, o por regímenes postautoritarios mediante decretos presidenciales, en uso de facultades extraordinarias concedidas por los parlamentos. En el año 2000 , las protestas en Cochabamaba y otras ciudades de Bolivia, por la privatización del agua, que había sido vendida a Betchel, una empresa norteamericana, paralizaron dicha ciudad por varios días. El gobierno respondió enviando tropas de choque y se calcula que hubo al menos dos docenas de muertos $y$ cientos de heridos (Cedeña 2000). Finalmente, el gobierno anuló la ley de privatización de dicho servicio. En El Salvador, durante 
nueve meses, entre septiembre de 2002 y junio del 2003, se realizó una huelga del personal del Instituto de Salud para evitar la privatización de la salud pública, quienes no se amedrentaron frente a las amenazas del gobierno y la privación de salarios durante ocho meses, hasta lograr que el gobierno retirara el proyecto del parlamento.

Los mismos argumentos se repiten en todos los países: las funciones empresariales corresponden al mercado y no al Estado; las empresas públicas son casi siempre deficitarias; son fuente de corrupción y de clientelismo político; son ineficientes; carecen de capacidad de inversión y crecimiento; es necesario aumentar los espacios del mercado; las privatizaciones son un requisito necesario para tener una economía abierta y globalizada; su venta es necesaria para financiar el gasto social, etc. Aunque algunas de estas razones sean parcialmente verdaderas, siempre habría la posibilidad de disminuir sus limitaciones. Pero, la ortodoxia neoliberal no acepta esa posibilidad, acude a sus creencias teológico-políticas y demoniza las empresas públicas a la vez que angeliza las privadas. En unas ve la encarnación del mal y en otras la mítica mano invisible de la Divina Providencia, que habría descubierto Adam Smith. Se reitera incansablemente que toda privatización aumenta la libertad económica; es beneficiosa para el mercado, para las economías nacionales y los usuarios.

La Comisión Presidencial para la Reforma del Estado de Venezuela es una de las más imaginativas, puesto que cree que las privatizaciones pueden contribuir a: “a) Mejorar la distribución del ingreso y la riqueza. De manera directa al permitir la aparición de nuevos propietarios y accionistas. De manera indirecta, al facilitarle al Estado la concentración gerencial y de recursos en políticas de mayor impacto social; b) fortalecer la sociedad civil al abrir nuevos espacios para la participación ciudadana" (1990 cit. Ojeda 1992: 128). El periódico El Universo de Ecuador, por su parte, ve el proceso de las privatizaciones como el cuento de la Cenicienta: "Ios políticos de finales del siglo XX han descubierto cómo lograr la magia de la privatización. La empresa estatal lerda, menos rentable, puede transformarse de un día para otro en próspera al aplicar la palabra mágica. Esa palabra milagrosa es "privatización" (Romero 1990, cit. Ojeda 1992: 91).

Este es un discurso ideológico en un doble sentido. De una parte, apela a intereses generales de la sociedad, de otra, constituye un intento de legitimar la decisión política de privatizar, cuyo real objetivo es la desnacionalización de las economías periféricas, el crecimiento de las transnacionales, y el fortalecimiento del empresariado local. Los efectos negativos económicos y sociales para la mayoría son siempre negados y minimizados. Un estudio sobre el tema de las privatizaciones en la prensa ecuatoriana muestra que "excepcionalmente, unos pocos articulistas consideran conveniente alcanzar ciertas condiciones para garantizar la privatización, ya que, de lo contrario, podría gene- 
rarse una mayor concentración económica, por ejemplo al vender las empresas públicas a unos pocos grupos económicos" (Ojeda 1992: 94).

Los gobiernos no asumen sus responsabilidades, ni tampoco una actitud racional, pues nunca evalúan si las privatizaciones produjeron los efectos positivos esperados, y no lo hacen porque temen o saben que sus promesas o expectativas no se cumplieron en la realidad, o bien porque, más allá de todo argumentación racional, están decididos a seguir privatizando. Por ello, los programas privatizadores continúan realizándose, ignorando las críticas, y los análisis de las consecuencias de las ya realizadas, que han efectuado cientistas sociales independientes. Todo esto es un notable ejemplo del carácter dogmático que asume la ortodoxia neoliberal en nuestros países, y expresa la profundidad de la dependencia de las elites gobernantes latinoamericanas a "los requerimientos de la globalización". Esta es una versión actualizada de la ideología civilizadora y modernizante: se quiere creer que ellas representan el progreso y la modernidad. Esta "tesis civilizatoria" e imitativa fue inaugurada por Sarmiento, Alberdi y otros el siglo XIX.

Escribe John Gray, un importante teórico liberal inglés, develando el carácter “leninista” de la argumentación neoliberal: “Hoy, el libre mercado global construido a raíz del colapso soviético también se está desintegrando, y por razones similares. Los neoliberales son deterministas económicos, igual que los marxistas. Creen que todos los países están destinados a adoptar el mismo sistema económico y, por ende, las mismas instituciones políticas. (Piensan que) Nada puede impedir que el mundo se convierta en un inmenso mercado libre, pero el inevitable proceso de convergencia puede acelerarse. Los gobiernos occidentales y los organismos transnacionales pueden ser las parteras del nuevo mundo. Por improbable que parezca, esta ideología sustenta instituciones tales como el Fondo Monetario Internacional. La Argentina e Indonesia tienen problemas muy diferentes, más para el FMI la solución es la misma: ambas deben convertirse en economías de libre mercado" (2003).

Sin embargo, no se trata sólo de una obstinada ilusión ideológica. La privatización de empresas públicas es una exigencia permanente a los países periféricos de parte del Fondo Monetario Internacional, el Banco Mundial, el Banco Interamericano y la Organización Mundial del Comercio, no sólo por razones ideológicas, sino porque las privatizaciones permiten comprar a bajo precio empresas de alta rentabilidad que producen servicios o productos de demanda rígida. Por ello, son un componente básico de la globalización, entendida como el crecimiento y expansión de las empresas transnacionales.

Las políticas que promueven los organismos económicos internacionales en los países periféricos serían y están siendo rechazadas por las sociedades de los países desarrollados, por ejemplo, pese a sus esfuerzos, la ex 
81/

믈

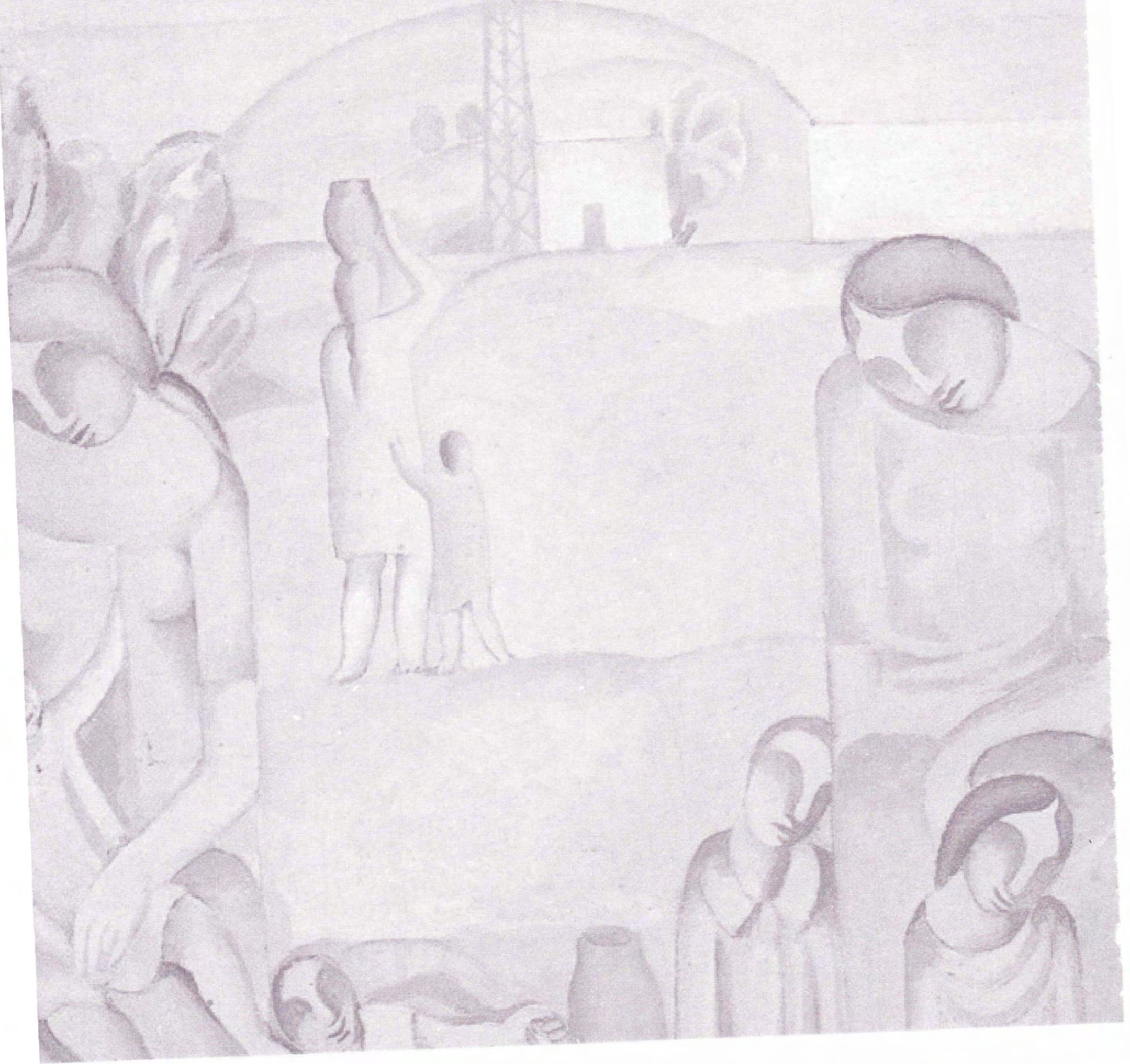


pues, de todos modos, disminuirá el valor de los bienes intermedios para la industria; (g) facilitar la inversión extranjera directa que se supone que no sólo traería capitales, sino capacitación y know-how para la producción de bienes y servicios para el mercado interno y la exportación; (h) privatizaciones de empresas públicas, especialmente de servicios, pues se cree que las empresas privadas se administran más eficientemente que la públicas; éste es un dogma de fe para el Consenso de Washington; estas privatizaciones constituirían una fuente de ingresos de corto plazo para el Estado; y se argumenta, que en el largo plazo, el Estado se libera de la responsabilidad de financiar ulteriores inversiones; (i) desregulación del proceso económico, evitando las interferencias de los burócratas, frecuentemente corruptos que perjudican a los medianos y pequeños empresarios (Ibid).

Fred Rosen, ex director de la revista Nacla, Report on the Americas Rosen, expuso las conclusiones de un congreso, celebrado en Antigua, Guatemala, convocado por el Grupo de Trabajo Sobre la Política Económica Internacional de la Universidad de Columbia: “Según muchos participantes, el Consenso de Washington es un modelo que vive en los cielos de la abstracción, afuera de la realidad. Es un modelo en el que ni existen instituciones políticas, ni mercados concretos, ni instituciones legales, ni historia alguna. Es un modelo que niega la necesidad de armar un campo de investigación especializado en "economía del desarrollo" porque, afirma, el estudio de la economía es igual en todas partes. Es un modelo que produce recomendaciones políticas "unitalla". En definitiva, es un modelo que no toma en cuenta la importancia de las necesarias instituciones para construir una economía, ni de las normas sociales, ni de los mecanismos legales, ni de las variadas estructuras de las economías del mundo. Los países "avanzados", aseveró el economista coreano de la Universidad de Cambridge, Ha-Joon Chang, no construyeron sus avances por medio del llamado mercado libre, sino mediante intervenciones estatales deliberadamente encaminadas a fomentar sus propias industrias y ventajas. Comentó que el lema de los países ricos que promueven las reformas del Consenso de Washington debe ser: "Haz lo que decimos, pero no lo que hicimos" (Rosen 2002).

El referido economista señala, en un artículo, que: “el hecho es que los países ricos no se desarrollaron sobre la base de las políticas e instituciones que ahora recomiendan a los países en desarrollo. Virtualmente, todos ellos utilizaron protección arancelaria y subsidios para desarrollar sus industrias. Una vez que se hicieron ricos, estos países comenzaron a demandar que los más pobres practicaran el libre comercio y adoptaran instituciones "avanzadas", si era necesario a través del colonialismo y de tratados injustos. Friedrich List, el principal economista alemán de mediados del siglo XIX, argumentaba que, de este modo, los países más desarrollados querían "derribar la escalera" con la que habían subido a lo alto 
y negar a los países más pobres la oportunidad de desarrollarse" (2002).

Ha-Joon Chang muestra que las políticas neoliberales del Consenso de Washington, entre las que se cuentan las privatizaciones de empresas públicas no han producido el aumento de los niveles de crecimiento que prometieron y siguen prediciendo. En una entrevista reciente, aseveró que "en América Latina, el ingreso per cápita entre los años 1960 y 1970 , en los días de la industrialización mediante la sustitución de importaciones (ISI), creció a 3,1\%; en cambio, entre los años 1980 y 1990, cuando América Latina abandonó la ISI (la política de sustitución de importaciones) con una fuerte presión del FMI y del Banco Mundial (BM) (que son controlados por los países ricos), y se ciñó al neoliberalismo, su ingreso per cápita creció solamente a 0,6\% Lo mismo ocurrió en otros países en desarrollo, en los que el ingreso per cápita entre los años 1960 y 1970 estuvo creciendo a $3 \%$, pero solo creció a 1,5\% entre los años 1980 y 1990, cuando la mayoría se ciñó al neoliberalismo. Además, este porcentaje no hubiera sido posible sin el gran crecimiento de China e India, países que definitivamente no siguieron las políticas neoliberales" (2003).

El programa de privatizaciones en Chile Influidos por estas teorías, los economistas neoliberales de Pinochet dirigieron un amplio programa de privatizaciones durante los 17 años del régimen militar, que incluyó no sólo empresas productivas agrícolas e industria- les, sino los servicios domiciliarios, la previsión y, parcialmente, la salud y la educación. En 1973, el Estado chileno poseía una gran cantidad de empresas. Las más importantes habían sido creadas por el mismo Estado durante los años cuarenta y cincuenta del siglo pasado, en aplicación de una política desarrollista, y las menores las había adquirido entre 1964 y 1973. Estas últimas, incluyendo las agrícolas, fueron devueltas a sus antiguos dueños, sin que reintegraran lo ya cancelado por el Estado, situación que significó grandes pérdidas para éste.

La más onerosa de las privatizaciones ha sido la concesión de los yacimientos mineros, la mayor riqueza natural no renovable del país, cuyas ganancias e impuestos constituían uno de los principales ingresos del Estado. Se privatizaron a bajo precio y el $63 \%$ de las reservas de cobre fue entregado a Exxon y otras empresas. El Estado se reservó sólo el $37 \%$ de la producción de yacimientos antiguos, lo que aún constituye una importante fuente de ingresos. Durante más de 25 años, la mayor parte de dichas empresas no han pagado impuestos, declarando que trabajan a pérdidas, lo que ha sido aceptado por todos los gobiernos, incluidos los democráticos que han gobernado desde 1990. El senador Jorge Lavandero, de la Democracia Cristiana, partido de la coalición gobernante en Chile, ha denunciado que sólo 3 de las 47 empresas que explotan gran minería en Chile pagan tributos (Gutiérrez 2003). Sólo las ganancias de Exxon en estos años han excedido los 3 mil millones de dólares. Un caso paradigmáti- 
co es el de la Empresa Minera El Indio de la Barrick Gold: durante 16 años, declaró pérdidas y ahora, que se agotó la veta de oro, la mina cerró "sin haber pagado jamás ningún tributo que favoreciera a nuestro país", dice el mismo senador (Ibid).

Por su parte, el diputado conservador de Renovación Nacional, Carlos Vilches dice: “en tal sentido daré un ejemplo muy claro. Durante el período 1990 - 2001, Codelco entregó al Fisco unos US\$ 10.659 millones, por su parte las mineras privadas sólo aportaron US $\$ 1.638$ millones, es decir, un 15\% del aporte de Codelco. Lo paradójico es que en este período la producción de las empresas privadas ha sido, en total, un $25 \%$ mayor que la registrada por Codelco. En resumen, si las empresas privadas hubieran pagado el mismo impuesto por tonelada que pagó la minera estatal durante ese período, el Fisco habría recibido unos US \$10.645 millones. A mi juicio habría elusión de impuestos bajo ciertos subterfugios legales. En este mismo escenario me refiero a lo que fue la venta de la minera Disputada de Las Condes, propiedad de Exxon, que en 22 años de operación en Chile, no había pagado impuestos al Estado. Este hecho refuerza toda iniciativa que deba emprenderse en tal sentido" (Vilches 2003).

La sobreexplotación del cobre ha mantenido muy bajo el precio del metal, con pérdidas de miles de millones de dólares para el Estado chileno. Lavandero señala que: «los organismos de gobierno están infiltrados por funcio- narios que representan los intereses de las grandes empresas del cobre, para que se perpetúe un sistema donde se busca fundamentalmente no arrojar utilidades en Chile para demostrar sólo pérdidas, y así no pagar durante años los impuestos que establece la ley" (Entrevista en Gutiérrez 2003). Este año se discutió sobre el modo de cubrir el déficit de 400 millones de dólares por la eliminación del impuesto aduanero a los productos de Estados Unidos, de acuerdo al nuevo tratado de libre comercio. El Ministro de Hacienda, Nicolás Eyzaguirre, ex funcionario del FMI, determinó que debía subirse el impuesto al valor agregado del 18 al $19 \%$. Dicho aumento de impuesto es un subsidio pagados por los consumidores para aumentar las utilidades de los importadores. Daña especialmente a los sectores de menores ingresos. Varios partidos de gobierno, el Partido Demócrata Cristiano y el Partido por la Democracia, habían propuesto que se aplicaran royalties a las compañías mineras. Se produjo una airada reacción de dichas empresas que aseguraron que esto arruinaría al sector, apoyados por la influyente prensa conservadora, y los partidos conservadores de oposición. El Ministro de Hacienda impuso su criterio. Posteriormente, el gobierno cambió de postura e impulsó una ley de royalties muy bajos que no obtuvo la aprobación del parlamento.

La privatización de las empresas de servicios domiciliarios y de transporte ha sido muy negativa. En los setenta, se cerró la Empresa de Transportes del Estado de buses urbanos 
para favorecer los empresarios privados de la locomoción colectiva y, asimismo, el Estado renunció a establecer una regulación que otorgara un mínimo de calidad a este servicio. Las ciudades se llenaron de buses, de bajísima calidad, verdaderos camiones carrozados, que usan diesel, el combustible más contaminante. Dichos vehículos tienen largísimos recorridos, y casi todos pasan por el centro de Santiago. Su número excede con creces a los necesarios, si se establecieran frecuencias y velocidad regulares, pues el Estado no puso límites a su crecimiento, ni ha sido capaz de establecer regulaciones mínimas. La ideología subyacente fue explicitada por Pablo Longeira, uno de los principales líderes de la Unión Demócrata Independiente, de extrema derecha, quien sostuvo que las actividades lícitas no deben tener limitaciones. El precio del boleto es de casi sesenta centavos de dólar, lo cual es desproporcionadamente alto en un país donde el sueldo promedio mensual es de sólo 500 dólares. Su nivel de accidentes es muy alto por la insuficiente preparación de los conductores y sus pésimas condiciones de trabajo. En consecuencia, la locomoción es cara, insegura, lenta, y muy contaminante. Si no fuera por el tren subterráneo -que es una eficiente empresa pública, que no alcanzó a ser privatizada durante la dictadura de Pinochet-, colapsaría el transporte público de la ciudad de Santiago.

Dicha ciudad, la capital del país con más de cinco millones de habitantes, es una urbe de calles estrechas y pocas avenidas grandes. El modelo ha estimulado la compra de automóviles, que se aproxima al millón de unidades, en detrimento del mejoramiento de la locomoción de superficie. Por tanto, muchas personas usan su automóvil para ir a trabajar durante la semana, a diferencia de lo que sucede en Berlín o París, por ejemplo. Asimismo, hay pocos lugares de estacionamientos y el precio por su uso es relativamente alto, por tanto hay muchos vehículos estacionados obstaculizando el tránsito. El resultado de todos estos factores es lamentable: durante las horas de mayor movimiento se producen atascos, el promedio de velocidad sigue disminuyendo; los vehículos contribuyen a la contaminación atmosférica, una de las más altas del mundo, y la acústica, también muy elevada. La solución elegida por el gobierno es, nuevamente, la privatización de las vías y la de licitar autopistas dentro de la ciudad, las que funcionarán con cobro electrónico de peaje. Para facilitar la aceptación de este sistema que significará por lo menos 70 dólares mensuales por el uso de una sola de estas autopistas dos veces al día, se ha abandonado el arreglo de las calles que lucen hoyos cada vez mayores.

El proyecto de la Costanera Norte, una de las principales autopistas licitadas, por sus diversas consecuencias negativas, fue resistido por las organizaciones de la sociedad civil durante varios años, y cuestionado por expertos independientes, e incluso por varias municipalidades. Este conjunto de fundadas críticas obligaron al Ministerio de Obras Públicas a mejorar el proyecto, para disminuir 
su negativo impacto ambiental. Pero, esto encareció el proyecto, y el Estado destinará más de 150 millones de dólares para subvencionarlo y garantizará una alta tasa de ganancia a la concesionaria. El principal diario conservador, El Mercurio, se pregunta, con un dejo de ingenuidad modernista: “Pocos pueden abstraerse del orgullo de ver cómo Santiago es cruzado por rutas expeditas, como se limpian las aguas servidas del Mapocho, pero ¿verdaderamente podemos pagar toda esta modernidad? ¿No estamos cargando demasiado el bolsillo de los asalariados, la capacidad real de pago de los consumidores?" (Sáez 2003: B1).

La principal compañía telefónica del país fue vendida a bajo precio a la Telefónica de España. En Chile, al cobro del servicio local medido se agregan mensualmente 10 dólares por la sola conexión telefónica, 2 dólares por "equipo e instalación principal garantizada", y se cobran por las llamadas al servicio de informaciones. En síntesis, el servicio domiciliario local es más caro que en Miami, donde los ingresos promedio quintuplican los de Chile. "Telefónica presentó, el viernes 7 de noviembre del año pasado, su propuesta tarifaria, donde pidió a la autoridad regulatoria que el minuto de llamada se incrementará $58 \%$ de día, 307\% de noche y $61 \%$ de madrugada" (Sáez 2003: B1). En estos años ha aumentado notablemente la cantidad de líneas fijas, pero dicha expansión se ha hecho subiendo las tarifas urbanas. Otra modalidad usada por las compañías telefónicas en Chile para aumentar los precios de la llamada ha sido abaratar el precio de los teléfonos móviles. Sin embargo, el precio por minuto para llamar a uno de esos teléfonos, dentro del país, es el mismo que en la Comunidad Europea. De este modo, resulta más caro llamar a un teléfono móvil en Chile que telefonear a Europa o Estados Unidos. Las compañías telefónicas en Chile son las peores evaluadas por los usuarios, especialmente por cobros indebidos.

La privatización de las empresas productoras y distribuidoras de electricidad también implicó un notable aumento de tarifas, las que son actualmente similares a las que se cobran en Alemania, cuyos salarios promedios también quintuplican los nacionales, con el agravante que las empresas no garantizan el nivel normal de abastecimiento en tiempos de sequía cuando disminuye la producción de electricidad provenientes de plantas hidroeléctricas. La principal empresa, de capitales españoles, se niega a crear nuevas plantas de otro tipo porque sus costos de producción son mayores que las hidroeléctricas, y el Estado no puede obligarlas a asegurar el creciente consumo. Dichas empresas invierten sus utilidades en comprar empresas similares en América Latina, sin mejorar su servicio en Chile.

En los últimos años se vendió la Empresa de Agua Potable, también a empresas españolas, aduciendo que el Estado no podía financiar el crecimiento de la empresa. Las tarifas se acrecentaron notablemente, mucho más que la tasa de inflación, y ya se está cobran- 
do adicionalmente casi 2,5 dólares, lo que equivale a un impuesto de $5 \%$ sobre el sueldo promedio nacional de 500 dólares para financiar la construcción de La Farfana, la nueva planta purificadora de aguas servidas, situada en áreas urbanas. El resultado ha sido lamentable. Para disminuir costos la empresa no cumplió con las normas mínimas de control, y los olores pestilentes contaminan una amplia zona urbana, sin que el gobierno sea capaz de obligar a dicha empresa a cumplir con la normativa vigente de higiene ambiental.

De este modo, la suma de los cobros de servicios domiciliarios de una familia de cuatro personas -que corresponde al promedio nacional-, superan los 100 dólares mensuales. "Una dura crítica al Gobierno, al que acusó de "recibir presiones y demorar injustificadamente la nueva ley corta eléctrica", formuló el diputado Carlos Vilches (RN). El parlamentario, que presidió la comisión de Minería y Energía durante gran parte de la discusión de la iniciativa legal, dijo que las señales económicas que la autoridad ha dado en los últimos meses "han sido erráticas en materia de transferencia y generación eléctrica”. Vilches afirmó que el Gobierno no ha aceptado legislar sobre materias fundamentales, como las compensaciones que deberán pagar las empresas generadoras y distribuidoras frente a un eventual corte de suministro, “porque intereses económicos han presionado para que ello no ocurra".
Sostuvo, que las multas no se pagan y los reclamos que llegan hasta los tribunales "no son resueltos, porque la legislación no es clara al respecto" (Entrevista a Vilches 2003).

La privatización de algunas grandes empresas productivas en los ochenta: la Industria Azucarera Nacional, la Compañía de Aceros del Pacífico, y otras se realizaron vendiéndolas bajo el precio comercial. Se calcula que las pérdidas para el Estado excedieron los 1.900 millones de dólares (Rev. Análisis 1991). Gran parte de sus acciones fueron compradas por funcionarios del régimen militar con préstamos excepcionales del Banco del Estado. Recientemente, se ha sabido que el propio Pinochet compró acciones de las empresas privatizadas, obviamente haciendo uso de información confidencial. Así se enriquecieron el ex dictador, sus ministros, altos funcionarios del régimen militar, y empresarios nacionales, entre ellos el ex senador Sebastián Piñeira, una de las principales figuras de la oposición conservadora (Monckeberg 2001).

El sistema previsional fue privatizado hace veinte años, en los ochenta. El régimen militar dictó una ley que obliga a todos los asalariados a inscribirse en alguna de las Asociaciones privadas de Fondos Provisionales (AFP), las cuales reciben $12 \%$ de la remuneración mensual. Estas empresas descuentan más del $20 \%$ de dichas cuotas previsionales por gastos de administración. Este es uno de los porcentajes más altos del mundo. Las pensiones que otorgan son muy bajas, alrededor del $20 \%$ de la última remu- 
neración, y hasta ahora en la mitad de los casos no alcanza al mínimo legal de 180 dólares, y el Estado debe subsidiarlas para suplir la ineficiencia social de dichas empresas. Dice el periodista económico Paul Walder: "El sistema previsional, que durante más de una década sólo fue objeto de deleite para los agentes financieros, bursátiles y la prensa especializada, hoy ha regresado a la agenda económica por otros motivos: el gran invento de la dictadura, el talismán financiero de José Piñera y Miguel Kast, ha devenido en un fiasco que amenaza con poner a la previsión como un pesado lastre estatal y transmutar a las nuevas generaciones de jubilados en modernos indigentes del siglo XXI. Esta situación es nueva para la gran mayoría de los cotizantes" (2004).

Una de las principales "modernizaciones" del régimen pinochetista en los ochenta fue la liberalización de la legislación para la creación de universidades privadas. Desde entonces ha disminuido el aporte fiscal a las llamadas "universidades tradicionales" que eran las públicas y privadas que existían antes de los ochenta. El Estado chileno destina sólo 200 millones de dólares a la educación superior, aproximadamente la sexta parte de lo que invierte el Estado venezolano; y sólo el $9 \%$ de lo que destina al presupuesto de las fuerzas armadas que alcanzó en el 2004, aproximadamente a 2200 millones de dólares. Desde los ochenta se han creado más de cincuenta universidades privadas, las cuales en su mayoría pertenecen a grupos empresariales, nacionales y extranjeros, y algunas al
Opus Dei y Los Legionarios de Cristo. Estos establecimientos actualmente atienden a más de la mitad de los doscientos cincuenta mil estudiantes universitarios, y cobran mensualidades que van desde los 200 a 600 dólares, según la carrera, en un país donde el ingreso promedio es de sólo 500 dólares. Por ello, se han creado líneas especiales de crédito en los bancos para pagar estas mensualidades las que comprometen por muchos años los ingresos familiares, y de los jóvenes profesionales.

Se ofrece un amplio repertorio de carreras, pero sólo en Santiago hay más de cuarenta escuelas de periodismo, derecho, ingeniería comercial y psicología, cuyos egresados tienen crecientes dificultades para encontrar trabajo. El resultado era esperable: el valor de la hora profesional tiende a disminuir en un mercado que crece mucho más lentamente que la cantidad de titulados, y se va produciendo una depreciación de los títulos y un aumento de la demanda de postgrados. Las universidades privadas son legalmente, fundaciones sin fines de lucro, y no pagan impuesto, aunque de hecho, casi todas ellas, funcionen con una lógica empresarial y muestren un impresionante ritmo de crecimiento de su infraestructura y en la cantidad de carreras.

En general, ingresan a ella los alumnos que han obtenido los puntajes más bajos en la prueba nacional de aptitud académica, sin embargo, su nivel de reprobación es mucho más bajo que en las universidades públicas, 
y su nivel promedio de calificaciones es sorprendentemente alto. No obstante, algunas carreras de algunas de estas universidades han logrado alcanzar un buen nivel académico. En promedio, su nivel de gasto en investigación es bajísimo, así como su dotación bibliotecaria, y funcionan casi exclusivamente con "profesores-taxis", contratados por cursos de cinco meses. La remuneración que reciben estos profesores -la mayoría de los cuales no ha realizado postgrado, ni tiene publicaciones-, es de alrededor de 1000 dólares por curso de cinco meses y, casi siempre se les cancela mediante el sistema de honorarios, con el cual no tienen cotización provisional.

En síntesis, los efectos negativos de las privatizaciones en Chile exceden en mucho sus consecuencias positivas, y refutan la teoría neoliberal que ve en ellas una fuente de eficiencia económica y bienestar para todos. Han significado enormes pérdidas al Estado, patrimonio de todos los chilenos; han sustituido monopolios públicos por monopolios privados poderosos sobre los cuales el Estado y los consumidores no tienen ninguna influencia; han aumentado indebidamente los precios de los servicios que es una de las causas del empobrecimiento de la población, y han constituido una fuente de corrupción, enriquecimiento indebido para los compradores de las empresas públicas, y los funcionarios implicados en su venta.

Las privatizaciones son un componente central del proceso de modernización neo- liberal en Chile, el cual se ha impuesto de modo extensivo, coherente y diversificado que durante treinta años. Este exhibe indudables logros macroeconómicos: crecimiento del producto, de las exportaciones, importaciones, niveles de consumo, baja inflación, y otros. Asimismo, ha habido indudables avances en los ítems incluidos en los índices de desarrollo humano: aumento en el ingreso per cápita, del nivel educacional, de los nacidos vivos, de acceso al agua potable, de las expectativas de vida, de acceso a la vivienda, y otros.

Sin embargo, esto no significa que hay aumentado inequívocamente la calidad de vida. La distribución del ingreso es una de las peores del mundo, compitiendo con algunos países africanos. El quintil de mayores ingresos concentra el $62 \%$ de la renta nacional. El ingreso promedio per cápita es de 4.600 dólares al año, lo que significaría que una familia promedio debería tener sobre 1.500 dólares mensuales, pero que en realidad el 70 \% o más de las familias están bajo esa cifra, lo que muestra el monstruoso grado de inequidad en la distribución del ingreso.

Se dice que uno de los grandes logros del modelo neoliberal en Chile es la disminución del nivel de pobreza, pero no se dice que ésta aumentó, justamente, con la aplicación de este modelo económico desde 1974, aunque ha disminuido desde 1990. Tampoco se dice que los indicadores de pobreza no corresponden a los estándares internacionales, pues en Chile se considera que una 
familia de cuatro personas ha "superado" la pobreza cuando su ingreso familiar sobrepasa a los 320 dólares mensuales. (Arribas y Vergara 2001). Sin embargo, un centro de investigación independiente, Terram de Santiago, realizó un estudio que muestra que una familia de cuatro personas, dado el nivel de precios existente, necesita mínimamente de 900 dólares, para cubrir los gastos básicos. Por ello, el nivel de endeudamiento privado con bancos, financieras y casa comerciales es crecientemente alto en los sectores populares y medios.

El nivel de la educación pública que atiende al $85 \%$ de los escolares es deficitaria, es así que el $75 \%$ de los adultos no puede comprender un texto sencillo que sí puede hacerlo un niño de 14 años en Suecia. La mayoría de la población no puede acceder a seguros públicos de salud eficientes y oportunos que aseguren una atención adecuada y accesible al nivel de ingreso promedio. La locomoción pública, la previsión, y el sistema judicial son caros y muy deficientes (Arribas y Vergara 2001).

\section{Reflexiones provisionales}

El análisis de las privatizaciones en nuestro continente muestra que éstas forman parte de un radical proceso de "un cambio de poder" (Tofler) a nivel internacional, y en cada una de las sociedades del mundo periférico, especialmente en América Latina, el cual se viene realizando desde fines de los setenta. Se confirma la interpretación de
Stiglitz. Las reformas neoliberales son, básicamente, un proyecto político: "El fundamentalismo del mercado se promueve en el tercer mundo, el mismo que jamás se intentaría en Estados Unidos y otros países desarrollados. Esto es nada menos que una agenda política que se promueve" (2002). Las supuestas ventajas que traerían las privatizaciones se han mostrado como parte de un discurso mitológico, que ha sido refutado por el análisis de sus consecuencias esperables e inesperadas. En la mayor parte de los casos los usuarios y ciudadanos han sido perjudicados por dichas privatizaciones.

El referido proyecto de dominación a nivel internacional significa la radicalización de la dependencia de las economías y los sistemas políticos del mundo periférico a las principales sociedades del Norte, y sus empresas trasnacionales, en función de nuevo ordenamiento de la economía y el sistema de poder mundial, en el contexto de una nueva revolución científico-tecnológica. Su diseño básico fue elaborado por la Comisión Trilateral, Brzezinski y otros, y continúa siendo complejizado y actualizado (Cfr. Trilateral 1977; Hinkelammert 1977, 2001 y 2004 b; Chomsky 2003; Vergara 2003 b y Foo Kong Dejo 2004 ).

Dicho proyecto ha constituido el núcleo de los procesos de globalización asimétrica, de las últimas décadas, que tienen como eje central el protagonismo económico de las corporaciones transnacionales y los organismos crediticios y de comercio internacional. El principal papel de los Estados de las 
naciones periféricas es el facilitar dichos procesos. Una de las principales vías es la de desnacionalizar y privatizar, en la mayor medida posible, no sólo las empresas públicas, sino sus sistemas previsionales, educativos, sus medios de comunicación, cárceles, caminos, vías urbanas, incluso sus parques y monumentos nacionales, etcétera, etcétera. Se trata de debilitar la función nacional de los Estados periféricos para someter a las poblaciones de las sociedades periféricas al poder ilimitado de los Estados y empresas del Norte.

Se trata de una "extraña dictadura"(Forrester) internacional y ubicua, que no tiene un solo centro estatal, sino que se realiza a la vez en lo estatal, y lo social; en los espacios públicos y privados, en las relaciones sociales, en las organizaciones, fuera de ellas y en el control invisible de la subjetividad y el deseo; que combina mecanismos macrofísicos y microfísicos, mediante múltiples formas de disciplinamiento y normalización (Cfr. Foucault 1975, 1979, 1999; Deleuze 1990 ; Forrester 1996 y 2000; Hinkelammert 2001 y 2004 a; Vergara 2003 b ). Esta extraña dictadura no requiere un Estado y partido totalitario, ni tampoco tiene una sola y explícita ideología oficial, aunque difunde y coloniza las conciencias con "un pensamiento único", y se ejerce impersonalmente mediante lo que Jünger llamaba "la dictadura del pensar económico", o Buchanan denomina “el imperialismo de la economía” (Hinkelammert 1977, Forrester 2000 y García de la Huerta 2004 a). No necesita ejercer el control completo, y explícitamente coercitivo de la producción y circulación simbólica e intelectual, aunque ejerce una "tolerancia represiva" (Marcuse) respecto a los comportamientos y mensajes disidentes y rebeldes.

El caso de Chile es paradigmático, no sólo porque fue el primero que aplicó radical, coherente e indiscriminadamente las políticas neoliberales contenidas en el "Consenso de Washington", sino porque ha logrado darle cierto nivel de estabilidad y sustentabilidad a su modernización neoliberal. Este es tal vez el único caso "exitoso" en América Latina, pero por ello muestra, a la vez, las limitaciones y miserias que conlleva este tipo de modernización en una nación periférica.

Sobre este caso, escribe el filósofo Marcos García de la Huerta, uno de sus críticos más perspicaces: "La capitalización acelerada mediante la liquidación de los activos públicos, tiene por objeto la implantación del nuevo poder soberano, que se llama así porque es la continuación de la política con otros medios, diríamos, parafraseando a Clausewitz. Son los negocios ahora los que continúan la política: ya no son necesarios los golpes militares, porque el poder queda virtualmente monopolizado, suprimida la separación entre el poder político y el económico, que dejaba cierto margen de autonomía para el primero. Pero, una vez comunicados ambos, el poder político queda sometido al económico y la democracia misma queda reducida a sus rituales periódicos, convertida en democracia electoral o procedimental. Cuando Hayek proponía "en lugar de 
democracia, una demarquía, un sistema en que el demos no tendría poder" (Hayek 1978), sin duda soñaba con algo por el estilo" (García de la Huerta 2004 b: 3 y 2004 a).

\section{Bibliografía}

Arribas María Inés y Jorge Vergara Estévez (2001), “Modernización neoliberal y organizaciones del Tercer Sector en Chile", Polis $N^{\circ} 1$, vol. 1, Universidad Bolivariana, Santiago de Chile

Caputo Orlando y Edgardo Condeza (2002), Desafío para el Ministro de Minería: revertir la desnacionalización del cobre, febrero, en "www.granvalparaiso.cl"

Ceceña, Ana Esther (2000), “La guerra del agua en Cochabamba" (Entrevista a AEC) en “http://www.ezln.org/revistachiapas/No14/ ch14herbas.html"

Chomsky, Noam (2003), “El mejor de los mundos, según Washington" en Los dueños del mundo, seleccón de artículos de Le monde diplomatique, Ed. Aún creemos en los sueños, Santiago.

Deleuze, Gilles (1990), “Post-scriptum sobre las sociedades de control" en Conversaciones, Ed. PreTextos, Valencia, 1995.

Diario La Tercera (2003), "Telefónicas móvi- les: cargos de acceso son bajos comparados internacionalmente", 20 de junio, Santiago.

Foo Kong Dejo, Herminia (2004), “La "guerra” contra Irak: Eurasia la variable oculta" en Polis $\mathrm{N}^{\circ} 7$, op.cit. Asimismo, en:

"www.revistapolis.cl".

Forrester, Viviane (1996), El horror económico, Ed. F.C.E, Buenos Aires, 1996.

Idem (2000), Una extraña dictadura, Ed.

F.C.E, Buenos Aires.

Foucault, Michel (1975), Surveiller et punir, Gallimard, Paris, 2000.

Idem (1978), La microfísica del poder, Ed. La Piqueta, Madrid, 1980.

Idem (1991), Saber y verdad, Ed. La Piqueta, Madrid.

Friedman, Milton (1962), Capitalism and Liberty, University of Chicago Press, Chicago.

Idem (1980), Free to Choose, Hartcourt Brace Jovanovich Inc., New York.

García de la Huerta, Marcos (2004 a), Pensar la política, Ed. Sudamericana, Santiago.

Idem (2004 b), "Privatizaciones" (art. inédito).

Gray, John (2003) “El fin de la historia toca a su fin" en "http://www.prometeolibros.com" 
Gutiérrez, Raúl (2003), “Mineras extranjeras propinan brutal golpe a Chile", en

"www.granvalparaiso.cl"

Ha-Joon Chang (2002), "La historia demitifica el libre comercio" en http://www.eleconomista.cubaweb.cu/2002/ nro187/187_403.html

Idem (2003)"Los organismos internacionales deben respetar la libertad de los países en desarrollo" (Entrevista) en la web de la Universidad del Pacífico de Chile: http://www.puntodeequilibrio.com.pe/ punto_equilibrio/_form/frm mail.php?id=15252\&bolnum_key=138serv_key=2100

Hayek, Friedrich (1959), The Constitutions of Liberty, University of Chicago Press, Chicago

Idem (1978), Nuevos estudios, Ed. Eudeba, Buenos Aires, 1992.

Hinkelammert, Franz (1977), Las armas ideológicas de la muerte, Ed. Sígueme, Salamanca, 1978

Idem (2001), El nihilismo al desnudo. Los tiempos de la globalización, Ed. Lom, Santiago.

Idem (2004 a), Solidaridad o suicidio colectivo, Ambientico Ediciones, San José de Costa Rica.

Idem (2004 b), El asalto al poder mundial y la violencia sagrada del imperio, Ed. DEI, San José.
Ips noticias (2003),"Especial de Inter Press Service - Privatizaciones" en http://ipsnoticias.net/focus/privatizaciones/ index.asp

Jimeno Pamela y Paula Mackensie (2003), "Gobierno da giro y se abre a presentar proyecto para impulsar royalty minero" en La Tercera, 20 de junio, Santiago.

Lucas, Kintto (2002), "Tribunal moral contra privatizaciones”, en http://www.rebelion.org/ economia/tribunal250901.htm"

Mises, Ludwig von (1927), Liberalismus, (Liberalismo, Ed. Planeta-Agostini, Buenos Aires, 1994)

Monckeberg, María Olivia (2001), El saqueo de los grupos económicos al Estado chileno, Eds. B, Santiago.

Ojeda, Lautaro (1992), Bondad y perversidad de la privatización. Opinión pública y publicada, Ed. ILDIS, Quito.

Popper, Karl (10934), La lógica de la investigación científica, Ed. Rei, Buenos Aires, 1989.

Panayotou, Theodore (1998), Eficiente valoración de los recursos mineros y captación de su renta en Chile (cit. por Revista Siete + siete No. 64,30 de mayo del 2003, Santiago).

Rev. Análisis (1991)"Así arruinaron la Corfo", reproducido en La Firme N ${ }^{\mathrm{a}} 293$, 25.3.2003, Santiago. 
Rivas, José Eudiviges (2003), “Las privatizaciones en Latinoamérica” en “http:// www.nadir.org/nadir/initiativ/agp/free/imf/ privatizaciones.htm"

Rosen, Fred (2002): 15 de noviembre www.caritaspanama.org/incidencia/ mundoquequeremos/ agonia_consenso_washington.hm

Sáez, Alejandro (2003), “La amenaza de las tarifas" en El Mercurio, Cuerpo B, 16 de noviembre, Santiago

Stiglitz, Joseph (2002), “Las políticas que imponen a países en desarrollo jamás las aceptaría el primer mundo", 17 de mayo, La Jornada, México D. F. Reproducido en www.rebelion.org/economia

Trilateral Commission (1977), Towards a Renovated Internacional System en www.trilateral.org

Vargas, René (2002), El Nuevo Diario, 13 de noviembre, Nicaragua, en

http://www.lainsignia.org/2002/noviembre/ econ_033.htm

Vergara Estévez, Jorge (2001) “La contribución de Hinkelammert a la crítica latinoamericana la neoliberalismo", Polis $N^{\circ} 2$, op.cit. Polis $\mathrm{N}^{\circ} 4$, reproducido en:

"www.revistapolis.cl"
Idem (2002), “El nihilismo al desnudo. Los tiempos de la globalización de Hinkelammert" en Polis $N^{\circ} 4$, op.cit. Asimismo, en: www.revistapolis.cl

Idem (2003 b),"Una extraña dictadura de Vivianne Forrester", en Laberinto $\mathrm{N}^{\circ} 13$, noviembre, Universidad de Málaga en Polis $N^{\circ} 6$, también en: www.revistapolis.cl.

Idem (2003 b),"La utopía neoliberal y sus críticos", en Laberinto $N^{\circ} 12$, julio, op.cit., también en Polis $\mathrm{N}^{\circ} 6$, en:

www.revistapolis.cl

Vilches, Carlos (2003), “Diputado Carlos Vilches aboga por colocación de royalty" (Entrevista) del 24 de mayo del 2003 en http://www.areaminera.com/Contenidos/ Entrevistas/entrevistas/125.act

Wiener, Raúl (2002), “Privatizaciones en Perú y Chile", 24 de octubre, en www.rebelion.org/economia 